\title{
ENTREVISTA
}

\section{Profa. Dra. Ester Cerdeira Sabino}

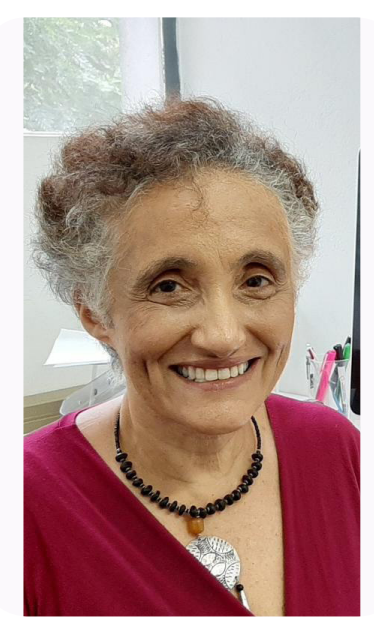

\begin{abstract}
Ester Cerdeira Sabino - Professora Associada do Departamento de Moléstias Infecciosas da Faculdade de Medicina da Universidade de São Paulo FMUSP. Diretora do Instituto de Medicina Tropical da USP de 2015 a 2019. Investigadora principal dos programas do NIH "Recipient Epidemiology and Donor Evaluation Study-IV Pediatric" e do "São Paulo - Minas Gerais Neglected Tropical Disease Research Center for Biomarker Discovery". Coordenadora do projeto PITE FAPESP "A Translational Study for the Identification, Characterization and Validation of Severity Biomarkers in Arboviral Infections" e do projeto FAPESP/MRC "The Brazil-UK Centre for Arbovirus Discovery, Diagnosis, Genomics and Epidemiology (CADDE)". Principais linhas de pesquisas: Segurança Transfusional, HIV, Doença de Chagas, Arboviroses e Anemia Falciforme. (Fonte: CV: http://lattes.cnpq. $\mathrm{br} / 8590492866942091)$.
\end{abstract}

Entrevista com a Profa. Ester C. Sabino para a Revista de Medicina do DC-FMUSP realizada no dia 06 de março, no Instituto de Medicina Tropical (IMT) da Faculdade de Medicina da Universidade de São Paulo (FMUSP), pelos acadêmicos Gabriel Vansuita Valente e Lucca Helmich, do grupo Gestor da Revista em 2020.

RevMed: A senhora poderia dar um panorama geral sobre o novo coronavírus?

Profa. Ester Sabino: Começou na China no final de dezembro de 2019, quando descobriram que havia uma epidemia; passou uma ou duas semanas e já sabiam que era um coronavírus. Quando você descobre um vírus, é difícil, não entende nada, não sabe como é. No início, pensou-se que seria como a SARS, porém, está se comportando bem diferente. É outro coronavírus que saiu de uma espécie animal e pulou para a espécie humana. Há sete coronavírus. Quatro circulam há muito tempo nos seres humanos e três causaram surtos epidêmicos. O primeiro foi a SARS (em 2003), que teve esse pulo interespécies. A mortalidade era muito alta. Conseguiram conter a epidemia. Depois teve a MERS (em 2012), coronavírus do oriente médio, transmitido por camelo, ainda em circulação, embora não no formato epidêmico, o que traz o temor sobre se transformar em epidemia novamente. Esse vírus é recente e pouco se sabe sobre ele: é preciso aprender tudo novamente, como funciona a sua patogenia, etc. Há vários fatores diferentes: fica doente de uma gripe, mas só piora depois de sete dias. Então, assim, toda transmissão vai depender da movimentação humana. A transmissão é por via respiratória, gotículas que ficam na superfície, que você contamina sua mão e, depois de tocar em alguma parte do corpo, se infecta. Onde tiver mais voo da China para aquele determinado lugar será onde primeiro receberá os casos positivos: Ásia, Singapura, Japão, Coreia agora, e depois Europa. Especificamente na Itália, 15\% do PIB é turismo. As pessoas viajam muito. Para o Brasil, a expectativa era de que primeiro chegasse na Europa e que depois se transmitisse para aqui, que é o que está acontecendo. Onde houver maior incidência de voos é onde acontecerá a epidemia. A gente está vendo aqui o que aconteceu na Europa há um mês. Estamos um mês atrás na epidemia da Europa. Precisamos olhar para a epidemia de lá e ver o que está acontecendo. Como aqui está mais quente, por conta do verão, talvez seja diferente. Mas, aparentemente, a gente tem vários outros vírus que se transmitem deste mesmo jeito e que passam aqui mesmo no verão, então não dá para ficar numa boa também.

Qual é o motivo de, repentinamente, termos toda essa visibilidade, de eu ficar famosa? Estávamos trabalhando com um grande projeto da FAPESP (Fundo de Assistência a Pesquisa do Estado de São Paulo), com apoio do MRC 
(Medical Research Council), a "FAPESP do Reino Unido", que dá recursos para o pessoal de Oxford, de Brighton e da London School; aqui, para o Instituto Adolfo Lutz, o SUCEN (Superintendência de Controle de Endemias), e Centro de Vigilância Epidemiológica. Da USP, não é só a Faculdade de Medicina: tem a Faculdade de Saúde Pública, a Poli (Escola Politécnica de Engenharia), o ICB (Instituto de Ciências Biomédicas). Nosso objetivo principal era arbovírus. Estávamos querendo montar essa técnica para fazer sequenciamento em tempo real, estávamos tentando montar para a dengue, porque a epidemia de dengue está começando. Quando veio o coronavírus, estava tudo montado no Instituto Adolfo Lutz. A sequência foi feita lá. O ideal é ser feito o sequenciamento, a epidemiologia molecular em serviços que fazem a vigilância epidemiológica.

RevMed: A senhora pode falar como foi o desenvolvimento dessa técnica?

Profa. Ester Sabino: Quando veio a epidemia de Ebola, o grupo do Prof. Nick Loman da Universidade de Birminghan tentou montar isso para o vírus. É um sequenciador bem pequenininho. Naquela época, do (vírus) Ebola, ele ainda era maior, mais caro. O que aconteceu: teve a epidemia de Ebola, eles queriam sequenciar o vírus. Um grupo foi com o sequenciador Illumina, que é um aparelho enorme, e eles com esse aparelhinho, para Serra Leoa - que não é um lugar que é fácil de você colocar um aparelho muito grande. Esse aparelho é bom para isso: vai para qualquer lugar. O pessoal até já levou para a NASA fazer sequenciamento, levaram para a Antártida para mostrar a capacidade. Teve a epidemia de Ebola e em seguida a de Zika. Aí, o pessoal que lidou com isso durante a epidemia de Ebola, que já tinha acabado, decidiu ir para o Brasil. Conseguiram o recurso do MRC para vir para aqui. Nós estávamos com algumas amostras de Zika que tinham vindo de Ribeirão Preto e ajudamos eles a montarem para o Zika. Eles fizeram uma viagem pelo Nordeste - foi um paper interessante, saiu na Nature em 2017 (nature.com/articles/nature22401) e que mostrava, por exemplo, que o Zika entrou no Brasil um ano antes de que tinha sido descrito. É um marco de epidemiologia. Só que desde então a gente queria fazer isso virar tempo real, ou seja, você conseguir fazer isso no momento que a epidemia está acontecendo. E o esforço então foi para fazer esse tipo de coisa, pensando em arbovírus. Nós já trabalhamos com as amostras de febre amarela, só que de novo: temos os dados depois que a epidemia acabou, não em tempo real. Agora, estávamos tentando fazer em tempo real para a dengue, que está começando.

RevMed: Quais são os benefícios de se fazer isso em tempo real?

Profa. Ester Sabino: Então, assim, sequenciar tem vários benefícios. Não necessariamente em tempo real, mas sequenciar em si. Porque te diz quando um vírus é divergente (se possui variabilidade genotípica dos demais), é importante para entender a diversidade do vírus, e isso pode ter impacto no desenvolvimento de vacina, para detecção de resistência a medicamentos, para teste diagnóstico. Em tempo real, é importante para você entender como o vírus está evoluindo. Então você consegue saber de onde estão vindo as cepas de uma determinada região. Dá para estudar se uma cepa é mais virulenta que outra. Então você monitora isso, o que te dá dados de como a epidemia está indo.

RevMed: Como está o estado, agora, das cepas do coronavírus?

Profa. Ester Sabino: Diariamente, diversos pesquisadores do mundo estão compartilhando na internet, por meio de alguns sites, os resultados dos sequenciamentos dos vírus que estão diagnosticando. Esse é o GISAID [professora Ester nos mostra o site, disponivel em gisaid.org]. As pessoas podem mandar os dados, fazer comentários - e foi aqui que a gente depositou e aqui que o pessoal vai submetendo as sequências. Então é público. No Nextstrain (nextstrain.org), você põe a sequência e, automaticamente, ramifica-se como em árvores; você pode até ver aqui como está evoluindo. Acho que eles pegaram amostras antigas e mostram onde está aparecendo. Vai aparecendo em qual região do genoma do vírus tem mais mutação, posição com mais variabilidade. Todo dia ele está sendo alterado com os números de sequências que entram. É o jeito da OMS (Organização Mundial da Saúde) ver o que está acontecendo. A primeira sequência do Brasil: Jaqueline Goes. As duas sequências do genoma viral (dos primeiros dois diagnósticos no Brasil) são diferentes entre si.

RevMed: São, então, dois eventos independentes de introdução do coronavírus, no Brasil?

Profa. Ester Sabino: Sim, e na Itália também. Estamos descrevendo o que está acontecendo na Itália, porque é de onde os dois vieram. Na Itália, já dá para ver bem que eles estão com epidemias bem diferentes. Aqui [Profa. Ester demonstra no Nextstrain] estão as sequências dos casos diagnosticados na Suíça, nesse braço. Quando a gente fez, ainda não tinha a Suíça; tem o México, e aqui a Itália também. Há poucas sequências da Itália ainda.

RevMed: Por que há poucas sequências da Itália?

Profa. Ester Sabino: Eu acho que eles estão enlouquecidos com tudo o que está acontecendo. Agora eles estão soltando as sequências, que estão parecidas com a da Inglaterra. Quando a gente colocou só aparecia a nossa com a da Inglaterra. Agora já estão aparecendo as outras e vai 
fazendo sentido para você entender de onde está vindo a epidemia.

RevMed: Quais são os desafios de fazer esse monitoramento em tempo real?

Profa. Ester Sabino: Eu acho que hoje a tecnologia não está tão cara. $\mathrm{O}$ que talvez limite seja a falta de reagente e importação aqui para o Brasil. Até hoje eu estava correndo atrás de importar mais material e ver se chega em tempo certo.

RevMed: Alguns países demoraram mais tempo para fazer o sequenciamento. $\mathrm{O}$ que a senhora acha sobre isso?

Profa. Ester Sabino: Depende de estar organizado. Se está preparado e pensando que isso irá acontecer. $\mathrm{E}$ ter as pessoas com expertise. Então, agora, o que a gente faz: alguns países da América Latina estão me pedindo para ir ensinar a técnica. Estou aqui falando que é preciso parar com essa história de dar entrevista para redes e ver com as pesquisadoras daqui quem pode ir para cada lugar. Porque estamos com uma série de pessoas já treinadas. Então a gente poderia ir, pelo menos os mais velhos, e os mais novos ficam aqui. Os mais velhos vão ensinando em outros lugares. Há uma com casamento marcado para dia 14. Eu falei: "mas você quer ir mesmo, você não vai se casar?".

RevMed: Professora Ester, o que a senhora acha do posicionamento da OMS sobre definir ou não a atual situação em pandemia?

Profa. Ester Sabino: Não tenho nem ideia. Não sei na prática qual a diferença entre definir ou não em pandemia. Não gostaria de criticar a OMS, o Ministério da Saúde, o Governo Estadual. No momento de crise, cada um tem a sua própria opinião, mas tem que seguir a regra do técnico do time. Tem que tentar, ao menos dentro do possível, ter um posicionamento geral. Epidemias tem razões políticas enormes. É só ver o que está acontecendo com os EUA. Uma confusão danada, ainda mais em ano de eleição.

RevMed: O que a senhora acha sobre o papel de tecnologias como a da plataforma de monitoramento BlueDot, que se utiliza de algoritmos baseados em inteligência artificial para avaliar notícias e identificar surtos de doenças - e que avisou seus clientes em 31 de dezembro sobre os casos do novo coronavírus?

Profa. Ester Sabino: Eu vi os caras passando uma mensagem. Na verdade, todo mundo está atrás disso. Não conheço essa plataforma especificamente, nem quanto eles vão cobrar para falar disso. Eles seguramente vão cobrar para te dar informação. E isso está acontecendo toda hora. Eu acho que é importante de se ter. O duro é se for um produto muito caro - tem que ter o seu valor, tem que pagar também, senão você não consegue manter as pessoas trabalhando lá. Precisa ver o quanto isso é factível para todo mundo usar. É isso, temos que achar mecanismos de predição de quando é importante ou não. Também, eles serem capazes de fazer uma vez não quer dizer que serão capazes de fazer sempre. Mas eu acho muito interessante. $\mathrm{Na}$ verdade, o Google tinha tentado fazer, pelo visto não foi tão eficiente. Nesse do Google, a pessoa faz o search da pesquisa de dengue e isso eles tentavam mostrar que batia com o tamanho da epidemia. Mas aqui no site do Bluedot parece que eles usam outras coisas além disso, não é só o search, mas as palavras, as notícias.

RevMed: A senhora acha que essas tecnologias deveriam ser usadas por órgãos de vigilância, deveriam investir mais nesse tipo de abordagem?

Profa. Ester Sabino: Um dos nossos objetivos também é fazer isso. A gente queria, na verdade, fazer com dengue. É um mapa que estamos fazendo, de um doutorado da engenharia da Poli, que estávamos tentando colocar em tempo real, que bateria com a filogenia da dengue. Estamos numa fase inicial. Os dados do CVE (Centro de Vigilância Epidemiológica, da Secretaria de Estado da Saúde do Governo do Estado de São Paulo) entraram desde 2007. Aqui [professora Ester apresenta em seu computador] você pode escolher nesse mapa o período que você quer analisar. Pode pôr o formato que você quer, aqui está no formato de cidade, e cada cor diz quantos casos há ao todo. Você pode ver o heatmap. Isso é uma coisa que a gente queria desenvolver. E há gente querendo trabalhar com mecanismos de predição. Dados, temperatura, tentando entender o que é importante. De uma forma que você consiga até chegar próximo ao local. Que ficasse de tal forma que o prefeito de Botucatu pudesse olhar cada semana e ver cada um desse lugares e entender onde estão os pontos da epidemia e se existe cluster, para poder intervir. A gente estava querendo fazer isso, estava focado nisso. Não estava focado em coronavírus nenhum - que até entendo muito pouco. Mas a ideia era isso. Ele [doutorando da Poli] disse: isso aí todo mundo já faz. O que ele quer fazer é a predição agora. Então ele pegou desde 2007 dados de toda epidemia em cada lugar e está tentando gerar um outro modelo de predição usando temperatura, mobilidade, número de mosquitos. O ideal seria que você falasse para o prefeito e que ele olhasse para o mapa e dissesse: ah, está aqui, eu tenho $90 \%$ de chance de ter uma super epidemia. $E$ É isso que a gente quer, o sonho. Talvez entender com esse pessoal [do Bluedot] para achar outras coisas que possam modelar melhor. Mas, sim, isso é tecnologia. Tem coisas que o pessoal está desenvolvendo. O que falta é a gente articular melhor, é necessário recurso maior e impacto que dê essa força. Na prática, o que estão fazendo com a pós a nível nacional... Hoje eu estava falando com uma 
pessoa da CAPES (Coordenadoria de Aperfeiçoamento de Pesquisadores de Ensino Superior): o que falar? Você tem algum aluno de pós-graduação da CAPES? "Não". Todo mundo é bolsista FAPESP.

RevMed: Em relação a essa epidemia atual, a senhora poderia comentar sobre quais estão sendo os métodos de contenção? Considerando que a China fez a quarentena na província de Wuhan.

Profa. Ester Sabino: Então, há duas coisas: ou funcionou a quarentena ou a epidemia ia acabar de qualquer jeito. Entendeu? A gente não sabe quantas pessoas se infectaram. Seguramente, em outros lugares da China não aconteceu. Então eu acho que a contenção que eles fizeram funcionou para eles, por enquanto. E eu falo por enquanto porque agora eles estão com medo de que volte (a epidemia) de outro lugar para eles. Porque, se não controlar aqui, eles vão fechar todos os voos e vão ficar mais um ano esperando passar no mundo inteiro? Senão vai voltar. É complexo isso. Talvez precise de medidas. O pessoal está começando a mudar um pouco o discurso. Acho que nos próximos dias é capaz de o Ministério mudar até um pouco o discurso. Cada momento as pessoas vão ter que repensar. Você está aprendendo na medida em que está acontecendo. Vai ser difícil.

RevMed: E, aqui no Brasil, está tendo alguma medida de contenção, o que está sendo feito com os casos?

Profa. Ester Sabino: Dos casos que chegaram, estão em casa parados. Teoricamente, não vai ter gente suficiente para ficar olhando se eles estão fazendo isso certo. Em quarentena também não tem onde arrumar. Onde vai colocar? Se a pessoa está bem e não há necessidade de internação, seguramente o hospital não é a melhor opção: um lugar caro e você põe os profissionais da saúde em risco para daí tirar esses profissionais do que precisam fazer. Eles devem ficar em casa, e seguir as recomendações. Vai ser bem difícil. Talvez tenha que, em algum momento, parar. A gente está discutindo se vai parar as aulas. Em que momento você deve parar as aulas? Em que momento você vai parar a cidade de São Paulo? Porque as pessoas também morrem de fome, a economia baixa também mata. Assim, não é uma doença que é muito pior que outras. O problema é acontecer todos os casos num único momento. Não tem como se preparar, porque não tem hospital para tudo isso. Mesmo em conta simples, se começar a pensar. Se vocês falarem que a mortalidade é $2 \%$, na classe de aula de vocês, significa que quatro pessoas irão morrer. Não é baixa. Você entendeu? Não é pouco. É lógico que para vocês (a letalidade) é menor que $2 \%$ - parece que é $0,4 \%$. Ainda assim é uma pessoa. Então não é pouco. Tem que pôr nesse contexto: que não é uma coisa simples.
RevMed: O fato do genoma viral desse segundo caso diagnosticado não ser tão próximo do primeiro significa que a transmissão ocorreu entre eles?

Profa. Ester Sabino: Sim, a gente já sabia, não precisaria sequenciar para isso. Mas se aparecer um caso que você não sabe de onde é, é possível comparar com as sequências que estão disponíveis. Por exemplo, o primeiro caso da Itália foi detectado em um turista em Roma, mas esta sequência não tinha nada a ver com as duas sequencias obtidas no Brasil. A epidemia na Lombardia começou através de mais de uma pessoa e não teve a ver com o primeiro caso detectado em Roma.

RevMed: Qual a importância de saber o paciente zero?

Profa. Ester Sabino: Ajuda você seguir e conter. Não que vá conseguir conter só com isso, mas dependendo você pode dizer: olha, esse paciente está transmitindo. Ficar de olho em quem são todos os contactantes, onde ele foi...

RevMed: No começo da pandemia estimava-se uma certa quantidade de pessoas para as quais uma pessoa infectada poderia transmitir o vírus, esse número mudou?

Profa. Ester Sabino: Eu acho que não, continuou a mesma coisa do R0 [número básico de reprodução] ser em torno de 2 .

RevMed: Como ainda não teve nenhum caso diagnosticado que se infectou aqui, todos os casos foram de infectados ligados ao caso um - ou que se infectaram fora do país, a situação aqui está um pouco mais controlada?

Profa. Ester Sabino: Há um mês a Itália estava mais ou menos assim, então...

RevMed: Diante dessa situação, você poderia dizer o que está sendo feito em termos de saúde pública em relação ao coronavírus agora e o que será feito depois?

Profa. Ester Sabino: Eu não estou nos comitês e não sei bem quais são os planos. "E se chegar, quando, o que será feito, o próximo passo, e se chegar tal número? Aí vai fechar a escola?". Eu acho que as pessoas estão pensando nisso e programando um plano. Aqui no HC (Hospital das Clínicas da FMUSP), onde eu participei um pouco mais, a gente fez uma programação de crise: eles têm um seguimento do que fazer em crise. Porque vai sobrar para cá os pacientes, a falta de máscara, de luva. Vai ter funcionário que vai ter doença e vai faltar. Pode ser que tenha funcionário com medo de vir trabalhar. Então tem toda essa trama que estamos nos preparando desde o mês de janeiro. Estão tentando abrir mais leitos de UTI. A quarentena será feita em casa. No hospital ficarão os casos de UTI, graves. 
RevMed: E esses casos graves, eles transmitem mais?

Profa. Ester Sabino: Transmitem menos. Às vezes estão ficando com PCR negativo [sem detecção do genoma viral no paciente] porque o vírus está ficando só no pulmão.

RevMed: Do ponto de vista do tratamento, como está sendo a pesquisa em torno de antivirais?

Profa. Ester Sabino: Eu sabia que estavam sendo testado três antivirais na China: o Ritonavir, droga para AIDS; uma droga que foi usada para o Ebola - e que não ficou tão boa no Ebola, mas que em vitro parecia que funcionava para esse, que é um inibidor de RNA polimerase - eles estavam tentando fazer antivirais que pegassem qualquer RNA polimerase; tem o da malária (cloroquina) que ninguém entende bem como funciona; e tem mais uma chinesa que não sei como funciona. Então tem pelo menos esses quatro.

\section{RevMed: E vacina?}

Profa. Ester Sabino: Já ouvi vários grupos falando que estavam no desenvolvimento de vacina. Até achei um bem interessante: eles falavam que agora estavam fazendo uma vacina com RNA. O que daí é muito fácil de fazer: você sintetizar RNA é uma coisa muito fácil hoje em dia, então você pode rapidamente pegar de um vírus para outro e produzir RNA. E não lembro o que era que tornava ela mais eficiente em produzir resposta imunológica. É uma boa tecnologia. Ainda não sei se já estão colocando para fazer testes.

RevMed: Agora, mudando um pouco o rumo, o que a senhora está achando do papel da mídia - tradicional, não tradicional? Como ela está transmitindo a informação da Universidade e dos pesquisadores para a população?

Profa. Ester Sabino: No último ano, as universidades públicas de São Paulo tiveram que responder a uma CPI na assembleia estadual. Os deputados queriam saber o que fazíamos na Universidade. Isso significa que a Universidade não está sabendo se comunicar com a sociedade! O que eu aprendi neste caso com essa repercussão dessas duas sequências é que nós temos que aproveitar os momentos e discutir ciência. Muitas vezes podemos achar que um resultado não é tão significante como descrever duas sequências de um vírus, mas se a população está interessada nessa notícia temos que usar este momento para mostrar o que fazemos e a importância da ciência. Quando publicamos na Nature as sequências do vírus da Zika não tivemos o mesmo impacto na mídia. Dessa forma, se a gente quiser uma universidade forte a gente vai ter que estar o tempo inteiro falando com a população, não tem conversa. É lógico, a gente tira um tempo, não precisa tirar tanto quanto tirou nessa semana, mas a gente pode, todo mundo, ir aos poucos falando e fazendo aparecer e mostrando. Agora mesmo saiu do Edison Durigon, do ICB, falando que eles isolaram o vírus. Isso é importante para fazer material de controle de qualidade. É isso: tem que mostrar. Quem sabe ele fica a próxima semana falando com os jornalistas. Eu trabalhei para divulgar ao máximo. Eu não quero que depois isso atrapalhe minha capacidade de fazer pesquisa de verdade. Espero que outros pesquisadores percebam. A gente tem que assumir que isso faz parte do nosso trabalho e que a gente tem que gastar uma parte do nosso tempo também divulgando.

RevMed: O que a senhora acha sobre a divulgação de informações falsas?

Profa. Ester Sabino: Então, é complicado porque eu não entendo como as pessoas conseguem gastar tempo com isso, de inventar coisa falsa. Alguns ganham com isso. Agora, essas fake news que vão por WhatsApp, o que esse cara está ganhando? Nem eles estão ganhando, a não ser perturbar. Agora, como que a comunicação humana sempre teve boato? É só que ela não tinha essa velocidade. Acho também que é recente o fenômeno, então, via internet. E por isso as pessoas ainda não sabem lidar com isso.

RevMed: Profa. Ester, a senhora acha que a facilidade na comunicação, pelas redes sociais, dificulta a transmissão de informações embasadas cientificamente?

Profa. Ester Sabino: É, tem isso. Tem uma coisa também. Não sei se é da geração de vocês, vale a pena até vocês depois analisarem e estudarem em termos de neurofisiologia. Eu acho que o cérebro de vocês já funciona diferente do nosso, e a comunicação com imagem, o pensamento por imagem e não por escrito mudou um pouco: eu acho que vocês processam mais imagem que coisa escrita e falada. Por isso vocês tem tanta dificuldade de seguir a aula. A gente não consegue... entendeu? É uma coisa geracional. A gente está quebrando a cabeça para ver como ensina e é bem difícil para nós ensinar e manter vocês prestando atenção. Eu dou mais aula para a pós-graduação. Como eu não fiz clínica, fica difícil dar aula. Eu fiz Pediatria e parei, fiz só seis anos - não vejo mais paciente, até tentei ir na clínica, preciso voltar, mas não deu tempo, com o pessoal do Departamento de MI (Moléstias Infecciosas). E eu acho que essa história do escrito com a imagem vai mudar muito. A comunicação é outra história: o que você fala e o que a pessoa entende. Seja lá se for escrita ou em imagem, no final você entende muito do que é o seu mundo, o que entra. Nem sei se a comunicação é possível, porque cada um entende o que quer, não o que você fala. Mas é difícil.

RevMed: Pensando em um assunto um pouco correlato, a senhora acha que essa disseminação de notícias falsas pode, em grande parte, ter associação com a educação científica 
da população?

Profa. Ester Sabino: Com certeza, mas isso não é só aqui. Esse negócio de notícia falsa você também vê lá nos EUA. O que está mais me preocupando com essa coisa de notícia falsa é como as pessoas querem manipular as outras usando fake news. Não sei se vocês viram Privacidade Hackeada [documentário de Jehane Noujaim e Karim Amer] - de como foi a eleição do Trump, do Brexit. A história é de um cara que, quando ouviu falar que a Cambridge Analytica tinha usado os dados para as eleições, quis que devolvessem seus dados, porque ele não os havia passado. Ele vai para a Inglaterra e abre um processo para receber os dados. A história é essa: então, ele conseguiu quebrar a empresa. Ela nunca devolveu os dados: "acho que não queria falar como os tinha obtido e o que sabia". A empresa faliu, mas você olha aquele (Steve) Bannon, ligado ao Trump, de extrema direita. É horrível, ele influenciou várias coisas: o Brexit, a eleição do Trump, depois aqui (Brasil), já estava fechando a empresa. É muito ruim o que eles fazem. E não quer dizer que eles não continuam fazendo. $\mathrm{O}$ fato de fechar uma empresa não quer dizer que acabou o problema: surgem outras usando o mesmo tipo de ferramenta. Vale a pena para ver e entender o mecanismo e como alguns desses boatos podem não ser à toa.

RevMed: Quanto à mídia, existe uma reação que está preocupada e aponta a seriedade da situação e uma que é contrária a isso: defendem que "a mortalidade do coronavírus é baixa, que é só mais uma gripe”. O que a senhora acha desses dois polos?

Profa. Ester Sabino: A Globo News me perguntou isso. Não pode ser 8 nem 80. Mas, façam as contas. Quanto vocês acham que é baixa a mortalidade? O pessoal falou em $2 \%$. Dois por cento $(2 \%)$ é letalidade. Isso é importante para aprender, que é diferente de mortalidade. A letalidade é a quantidade de pessoas que morreram dividida pelo número total de pessoas que pegaram o vírus e ficaram doente. A mortalidade é quantas pessoas morreram pela população geral - você não sabe quantas pegaram a doença. E isso é importante porque você nem sempre sabe exatamente quantas pegaram a doença. Quantas pegaram a doença em Wuhan? Não sabem. Quantos foram para o hospital você pode saber, mas quantos pegaram, realmente, você nunca vai saber. Então termina a epidemia e se fala; a mortalidade foi tanto. Quanto foi a mortalidade da gripe espanhola? Eu não sabia, aprendi agora: daquele horror que matou 50 milhões de pessoas, qual foi a taxa de mortalidade? Era $2 \%$. Eles imaginam que um terço da população se infectou. A gente tem que ver a população da época, e a mortalidade foi $2 \%$. Depois eles fazem o inverso e acham a letalidade, mas a mortalidade é fácil de medir: você sabe quantos morreram, você sabe a população, é fácil. E você pode comparar hoje, a gente podia tentar fazer isso. A epidemia estava em Wuhan, quantas pessoas morreram lá? Eu não sei qual a população para chegar à mortalidade. Eu sei qual é a população do Brasil, eu sei qual é a da cidade de São Paulo. Quantas pessoas vão morrer? O problema é todo mundo morrer no mesmo mês: sobrecarrega o sistema de saúde. Não vai ter saúde. Eu também acho que não é para ficar, assim, assustado, principalmente para a gente da área da saúde, que vai receber todo mundo.

RevMed: Então você diria que esse é o grande risco do coronavírus: afetar o sistema de saúde?

Profa. Ester Sabino: É, é o colapso do sistema de saúde. E aí vai acontecer que irão morrer não só as pessoas que chegaram lá infectadas pelo novo coronavírus: vai morrer quem tiver apendicite, porque não vai ter quem cuidar; vai morrer gente infartada... Então, esse é o problema. É uma combinação de fatores durante os três meses que durar. Lá (China) não durou tanto, está acabando agora a epidemia. Eles fecharam tudo e não foi para o resto da China. A gente pode fazer isso aqui: "ah, chegou aqui, fechamos São Paulo". Entendeu? Se é alarmista, não é alarmista, é algo discutível... Não vai morrer 16 milhões de pessoas, mas, se for $0,5 \%$, é bastante assim mesmo, e de uma só vez... a gente não sabe quantas pessoas irão pegar. Então, de qualquer jeito, vai sobrecarregar o sistema de saúde.

RevMed: Nesse novo coronavírus, há a característica de que, das pessoas que são infectadas, muitas necessitam de internação e evoluem para casos graves, é isso?

Profa. Ester Sabino: É isso, eles evoluem para casos graves, ficam intubados e por bastante tempo, o que sobrecarrega o sistema. O próximo que chegar não terá o aparelho de intubação: vai morrer em casa.

RevMed: Há a taxa de quantos são internados?

Profa. Ester Sabino: A gente teria que ter os dados bem montados da China, que provavelmente não teve o tempo de tabular tudo certo ainda, na loucura que foi. Até criaram hospitais. O dado deve ter sido muito difícil de manter, médicos morrendo... um negócio bem triste.

RevMed: O que a senhora acha que dos meios de prevenção pessoais: lavar a mão, usar máscara?

Profa. Ester Sabino: Tem que fazer. Eu notei que sem querer a gente começa a cumprimentar, dar a mão. É importante realmente não tocar e lavar a mão toda hora.

RevMed: Para finalizar a entrevista, há alguma coisa que a senhora gostaria de falar?

Profa. Ester Sabino: Então, a gente queria mais os alunos 
da medicina fazendo pesquisa [comenta rindo]. Quando você falou que era da medicina, pensei: é deles mesmo que estou atrás! Porque eu sei que é difícil, durante o curso de medicina, fazer iniciação científica, mas quem sabe vocês se interessem por essa área. É difícil médico se interessar porque não vê paciente, é muito longe disso, mas às vezes algum é como eu e gosta disso. Precisa saber que existe isso aqui e quem sabe se diverte com toda essa coisa de epidemia.

\section{Nota do Corpo Editorial}

Considerando o atual cenário, a atualização de informações e decisões em relação ao novo coronavírus é diária: desse modo, alguns pontos mudaram desde a data da entrevista (06/03/20). Um deles é o decreto de pandemia pela OMS em $11 / 04 / 20^{1}$. Outro é o crescimento na investigação e no interesse midiático na droga hidroxicloroquina para o tratamento de COVID-19, cujos resultados são limitados e inconclusivos até o momento ${ }^{2}$. Há ensaios clínicos em andamento com o objetivo de avaliar a eficácia desse e outros tratamentos: a administração de hidroxicloroquina ou cloroquina é uma das 4 terapêuticas estudadas no ensaio clínico "Solidarity" da OMS, que contava com a participação confirmada de 70 países em 27 de março de $2020^{3}$. Ainda, no decorrer do último mês saíram estudos que analisaram a importância de intervenções não farmacológicas para a redução da sobrecarga dos sistemas de saúde e, consequentemente, diminuição da mortalidade da COVID-19 - aqui, destaca-se o estudo do Imperial College London, de 16/03/20, responsável por orientar as medidas iniciais de distanciamento social em diversos países, sobretudo no Reino Unido e nos EUA ${ }^{4}$. No Brasil, o Ministério da Saúde definiu, em 06/04/20, os critérios para se fazer o distanciamento social no país, considerando os diferentes cenários de cada cidade, que valerá a partir do dia 13 de abril ${ }^{5}$.

\section{Referências}

1. World Health Organization (WHO). WHO Director-General's opening remarks at the media briefing on COVID-19 - 11 March 2020 [cited 2020 April 08]. Available from: https:// www.who.int $/ \mathrm{dg} / \mathrm{speeches/detai1/who-director-general-s-}$ opening-remarks-at-the-media-briefing-on-covid-19---11march-2020.

2. Yazdany J, Kim AHJ. Use of hydroxychloroquine and chloroquine during the COVID-19 pandemic: what every clinician should know - 31 March 2020. Ann Intern Med. 2020 Mar 31. doi: 10.7326/M20-1334.

3. World Health Organization (WHO). "Solidarity" clinical trial for COVID-19 treatments [cited 2020 April 08]. Available from: https://www.who.int/emergencies/diseases/novelcoronavirus-2019/global-research-on-novel-coronavirus2019-ncov/solidarity-clinical-trial-for-covid-19-treatments.

4. Ferguson NM, Laydon D, Nedjati-Gilani G, et al. Impact of non-pharmaceutical interventions (NPIs) to reduce COVID-19 mortality and healthcare demand. Imperial College COVID-19 Response Team; 16 March 2020. doi: https://doi.org/10.25561/77482

5. Brasil. Ministério da Saúde. Saúde define critérios de distanciamento social com base em diferentes cenários [citado 08 abri. 2020]. Disponível em: https://www.saude.gov.br/ noticias/agencia-saude/46666-ministerio-da-saude-definecriterios-de-distanciamento-social.

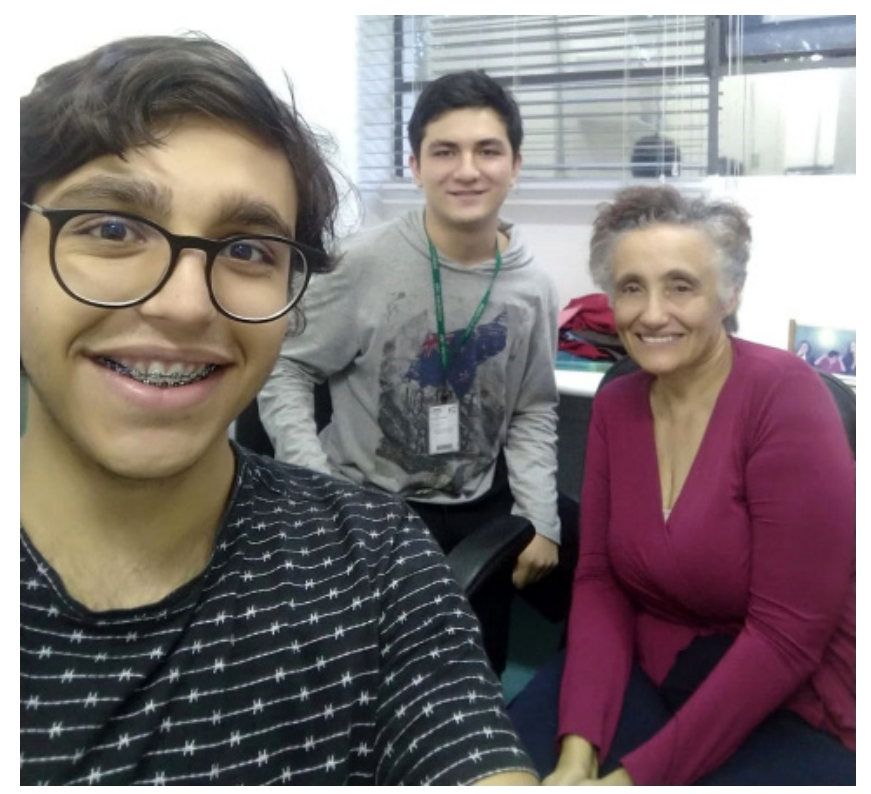

"Um agradecimento especial à professora Dra. Ester Sabino pela disponibilidade em nos conceder esta entrevista; a Célia Regina de Oliveira Rosa (bibliotecária do IGc-USP), à Júlia Carolina Campos Cardoso (internacionalista, ex-aluna do IRI-USP) e à Suely Campos Cardoso (bibliotecária FMUSP e da secretária executiva da Revista de Medicina), pelo auxílio prestado quanto à estruturação do texto". 